\title{
COMMENT
}

CONSERVATION EXperts weigh in on priorities for the world's protected areas $\mathbf{p . 2 8}$
ECONOMICS Loss of natural and ecological capital leaves hole in national budgets p.32
CHEMISTRY The fame and shame of the elements that never were $\mathbf{p . 3 4}$
AUTOBIOGRAPHY Carl Djerassi,

father of the Pill, reflects on his life and literature $\mathbf{p . 3 6}$

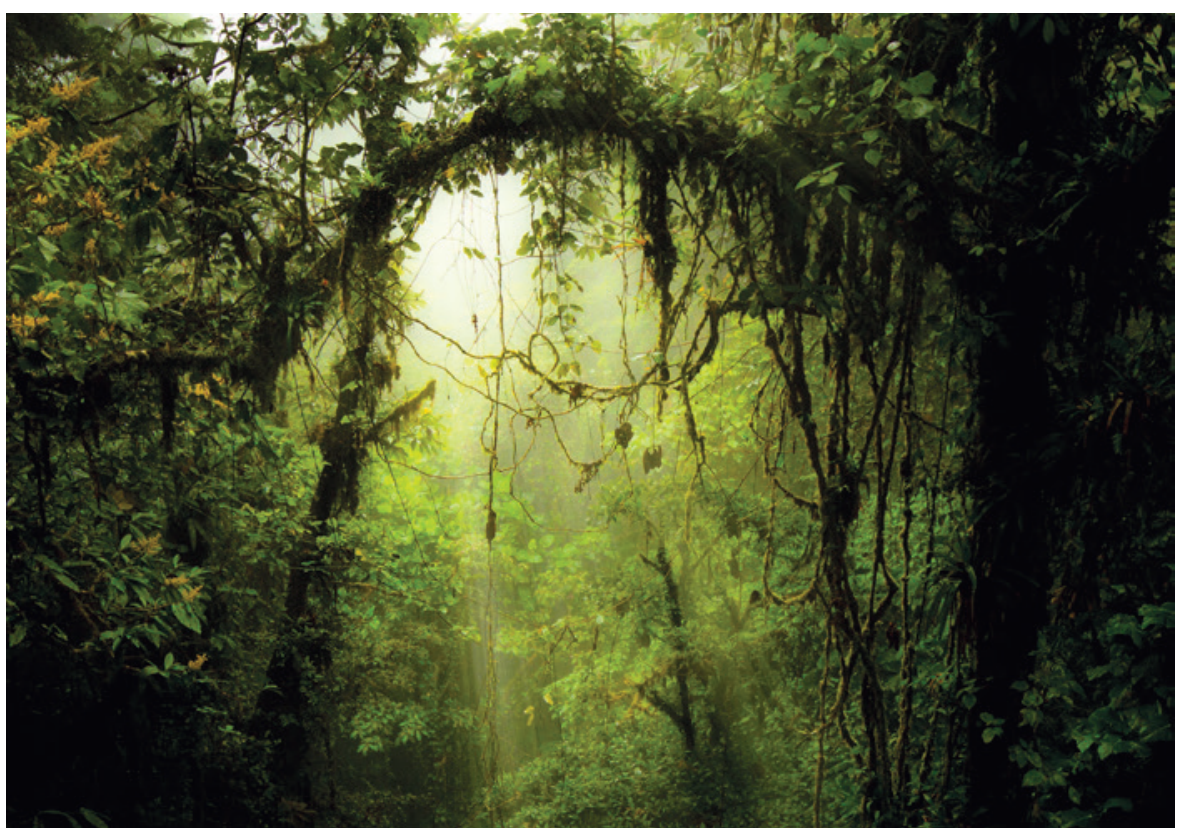

Conservation efforts risk getting snared in a tangle of aims.

\section{A call for inclusive conservation}

\section{Heather Tallis, Jane Lubchenco and 238 co-signatories petition for an end to the infighting that is stalling progress in protecting the planet.}

\section{A} $\mathrm{n}$ age-old conflict around a seemingly simple question has resurfaced: why do we conserve nature? Contention around this issue has come and gone many times, but in the past several years we believe that it has reappeared as an increasingly acrimonious debate between, in essence, those who argue that nature should be protected for its own sake (intrinsic value) ${ }^{1,2}$ and those who argue that we must also save nature to help ourselves (instrumental value) ${ }^{3-5}$.

Champions of instrumental value contend, among other things, that protecting nature for its own sake alone has failed to stem the tide of species extinction, that conservation should be open to partnering with business to effect the greatest change and that conservation support will be broadened by more directly considering other social objectives (such as food security or clean water). By contrast, advocates of intrinsic value assert that ethical arguments for conservation should be sufficient, that partnering with business is selling out to those who create the problem and that social considerations are already central to conservation.

Unfortunately, what began as a healthy debate has, in our opinion, descended into vitriolic, personal battles in universities, academic conferences, research stations, conservation organizations and even the media ${ }^{6}$. We believe that this situation is stifling productive discourse, inhibiting funding and halting progress.

Adding to the problem, in our view, is the issue that this dispute has become dominated by only a few voices, nearly all of them men's. We see this as illustrative of the bigger issues of gender and cultural bias that also continue to hinder conservation.

The stakes? The future of conservation science, practice and policy. Conservation regularly encounters varied points of view and a range of values in the real world. To address and engage these views and values, we call for more-inclusive representation of scientists and practitioners in the charting of our field's future, and for a more-inclusive approach to conservation.

\section{EMBRACE DIVERSE VALUES AND VOICES}

Women historically have been underrepresented in environmental-science faculty positions and in conservation practice, as in most scientific fields. This disparity is changing globally, but at different rates: more slowly in Asia and more quickly in Latin America and the Caribbean, for example ${ }^{7}$. In the United States, more than half the leadership positions in conservation organizations are now held by women. And on the global stage, women currently hold top positions in many leading efforts, including the Intergovernmental Platform on Biodiversity and Ecosystem Services, the Future Earth science committee, and the International Union for Conservation of Nature. This progress makes the dearth of female voices in the debate about the premise of our profession all the more stark.

The signatories in agreement here women and men from around the globe - support an equal role for women and for practitioners of diverse ethnicities and cultures in envisaging the future of conservation science and practice.

Together, we propose a unified and diverse conservation ethic; one that recognizes and accepts all values of nature, from intrinsic to instrumental, and welcomes all philosophies justifying nature protection and restoration, from ethical to economic, and from aesthetic to utilitarian. What we propose is not new. This diverse set of ethics has a long-standing history in modern conservation ${ }^{8}$. For 
vexample, more than 100 years ago, both intrinsic and instrumental values were used in the creation of Yellowstone National Park in Wyoming, and when Californians spurred the broader environmental movement in the United States by using economic studies of the value of birds alongside compelling speeches about the purity and grandeur of nature?

These values need not be in opposition, although they do reflect the hard choices that conservation often faces. They can instead be matched to contexts in which each one best aligns with the values of the many audiences that we need to engage. Those on the side of intrinsic value will argue that by recognizing the many ways in which people benefit from nature, we cheapen nature and miss opportunities to save components of it that have little or no obvious value to people. This is a valid concern, and one of many reasons why we must continue to uphold intrinsic values to audiences who share those values, or may be inspired towards them. However, instrumental values will remain more powerful for other audiences, and should be used in the many contexts where broadening support for conservation is essential ${ }^{4}$.

Clearly, all values will not be equally served in every context. Approaching conservation problems with representative perspectives and a broad base of respect, trust, pragmatism and shared understanding will more quickly and effectively advance our shared vision of a thriving planet. Prominent institutions already embrace multiple voices and values. For example, the field's signature international treaty, the Convention on Biological Diversity, calls for the conservation of biodiversity, and for the sustainable use and equitable sharing of its benefits. Some countries leading in this area, such as Mexico, Costa Rica and Colombia, have followed suit, capturing these joint interests in their own governing language.

\section{PRACTICAL ACTION}

What now? Academic training of conservation scientists should more accurately portray the rich, global history of the field, introducing students to the diverse ways in which nature has been valued and conserved for centuries. More forums at conferences, in journals and on social media are needed to elevate the voices of scientists and practitioners from under-represented genders, cultures and contexts. Conservation organizations and scientists can embrace all plausible conservation actors, from corporations to governmental agencies, faith-based organizations and interested individuals, and advance conservation efforts when they can benefit people and when there is no obvious human-centric goal.

These efforts must be underpinned by a stronger focus on synthesizing and expanding the evidence base that can identify what works and what fails in conservation so that we can move from philosophical debates to rigorous assessments of the effectiveness of actions. And we must encourage the full breadth of conservation scientists and practitioners to engage with the media so that coverage reflects the true range of opinion (for example, the 240 co-signatories listed are ready for interview) rather than the polarized voices of a few. To add your name to this petition, visit diverseconservation.org.

It is time to re-focus the field of conservation on advancing and sharing knowledge in all relevant disciplines and contexts, and testing hypotheses based on observations, experiments and models ${ }^{10}$. We call for an end to the fighting. We call for a conservation ethic that is diverse in its acceptance of genders, cultures, ages and values.

Heather Tallis is lead scientist at the Nature Conservancy in Santa Cruz, California, USA. Jane Lubchenco is professor of marine biology and of zoology at Oregon State University in Corvallis, Oregon, USA. e-mail:htallis@tnc.org

1. Gudynas, E. in La Naturaleza con Derechos: De la Filosofía a la Política 239-258 (AbyaYala, Universidad Politécnica Salesiana, 2011).

2. Soulé, M. Cons. Biol. 27, 895-897 (2013).

3. Reid, W. V. et al. Nature 443, 749 (2006).

4. Kareiva, P. \& Marvier, M. BioSci. 62, 962-969 (2012).

5. Toledo, V. M. \& Barrera-Bassols, N. La Memoria Biocultural (Icaria, 2014).

6. Max, D. T. 'Green Is Good' The New Yorker (12 May 2014).

7. UNESCO Institute for Statistics. Women in Science: UIS Fact Sheet (UNESCO, 2012).

8. Carson, R. Silent Spring (Houghton Mifflin, 1962).

9. Alagona, P. S. After the Grizzly: Endangered

Species and the Politics of Place in California (Univ. California Press, 2013).

10.Chapin III, F. S. et al. Ecosphere 2, 89 (2011).

For a full list of co-signatories and further reading on this topic, see go.nature.com/tezttv.

\title{
A to-do list for the world's parks
}

\author{
Experts share their priorities for what must be done to make \\ protected areas more effective at conserving global biodiversity.
}

BOB PRESSEY

Maximize returns on conservation

Professor, Australian Research
Council Centre of Excellence for Coral
Reef Studies, James Cook University

Protected areas are meant to preserve biodiversity, but practice, measures of progress and targets do not reflect this role.
Governments and non-governmental organizations usually concentrate on politically palatable measures, such as numbers of hectares. Measures of progress and targets for protected areas should focus on placing protection where it can make the most difference.

A 2008 study estimated that only 7\% of protected forests in Costa Rica would have been lost if not protected (K. S. Andam et al. Proc. Natl Acad. Sci. USA 105, 16089-16094; 2008). These forests, like most protected areas worldwide, are in 'residual areas' those where direct human threats to biodiversity are low, and where 'protection' makes little difference. Misleadingly, target 11 of the Convention on Biological Diversity measures progress in percentages of land and sea protected. Meanwhile, the biodiversity of contested places continues to be eroded.

Performance metrics for protected areas should borrow from those in medicine, education and development. These fields all aim to maximize returns on investment. The language of programme evaluators is framed in terms of efficacy: what is the actual outcome of an intervention, compared with the outcome expected from no intervention?

For protected areas, efficacy means 